\title{
Malignant melanoma in Scotland
}

\section{Introduction}

Skin cancer is the most common cancer in Scotland. There are two main types of the disease: nonmelanoma skin cancer and malignant melanoma. Non-melanoma skin cancer is relatively common, with 10,073 cases diagnosed in $2010^{1}$. Malignant melanoma is rarer in comparison, with 1,141 cases diagnosed in $2010^{2}$. However, it is more serious, leading to 176 deaths in 2011 , compared to 82 reported deaths for non-melanoma skin cancer ${ }^{3}$.

In recent years there has been increasing awareness and understanding among the public of the causes, signs and symptoms of skin cancer. This has been helped by the effective work of campaigners and policy-makers in Scotland. For example, the ban on the use of sunbeds by under $18 \mathrm{~s}$ in the Public Health (Scotland) Act 2008 will play a role in preventing melanoma.

The Scottish Government has made the early identification of cancers a strategic priority, with the launch of the Detect Cancer Early initiative in February 2012, supported by $f 30$ million in funding for social marketing and awareness raising ${ }^{4}$. However, to date, there has been no specific activity targeted at preventing incidence of melanoma through greater awareness of sun safety. This is occurring against a backdrop of rising incidence of malignant melanoma, with the number of people diagnosed with melanoma rising from 447 in 1986 to 1,141 in $2010^{5}$ and it has been estimated that the number of new cases of melanoma will rise by more than 1,500 between 2010 and $2016^{6}$. There remain significant challenges in terms of skin cancer prevention, as well as early diagnosis and the development of high quality NHS services for all those who need it.

This briefing provides an overview of some of the data on malignant melanoma incidence and outcomes in Scotland. It also includes a number of recommendations to reduce the burden of malignant melanoma and ensure patients living with the condition have the best possible outcomes and experiences.

\section{Statistics on malignant melanoma in Scotland}

\section{The incidence of malignant melanoma in Scotland}

In 2010, a total of 29,449 people in Scotland were diagnosed with cancer, of which 1,141 were diagnosed with malignant melanoma, making it the sixth most common cancer in Scotland ${ }^{7}$. This represents 3.9\% of all cases of cancer in Scotland ${ }^{8}$ and equates to a rate of 17.9 per 100,000 of population ${ }^{9}$.

Figure 1 shows that rates of malignant melanoma have increased over the last two decades, with slight falls in the mid-1990s and in 2005.

This briefing paper was been drafted on behalf of Skin Cancer UK by MHP Health Mandate

Full editorial control rests with Skin Cancer UK, however the final content has been reviewed for factual accuracy by Roche Products Ltd.

Funding for this project has been provided by Roche Products Ltd. 
Figure 1: European age-standardised rate (EASR) of the incidence of malignant melanoma by 100,000 population in Scotland, 1986-2010

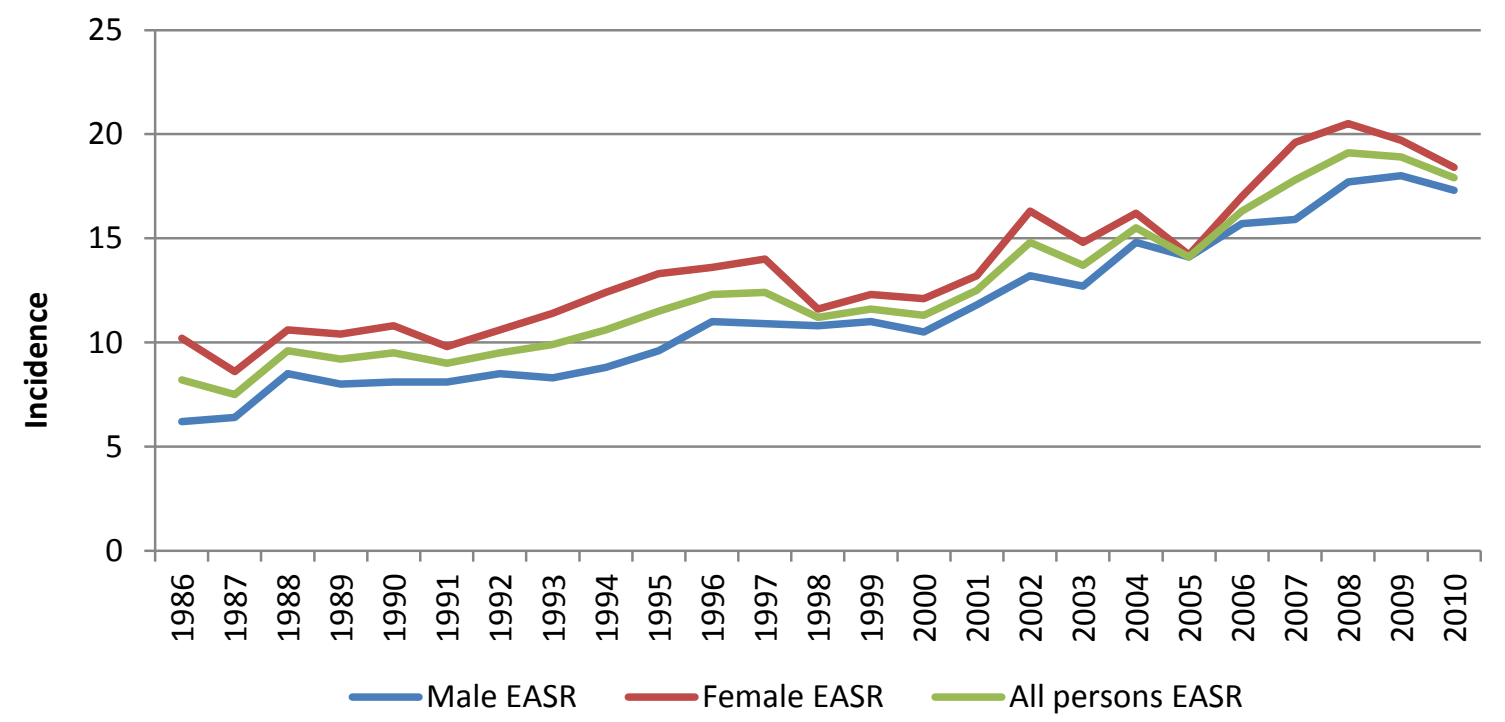

Malignant melanoma is more common in women than in men, with 524 cases of malignant melanoma in men in 2010, compared to 617 in women ${ }^{11}$. Malignant melanoma is also more common as people age, with the incidence increasing as people get older. However, for people in the 15-34 age group, melanoma remains one of the most common types of cancer, even though the incidence is lower than in older people.

Figure 2: European age-standardised rates (EASR) of incidence of malignant melanoma by 100,000 population in Scotland in $2010^{12}$

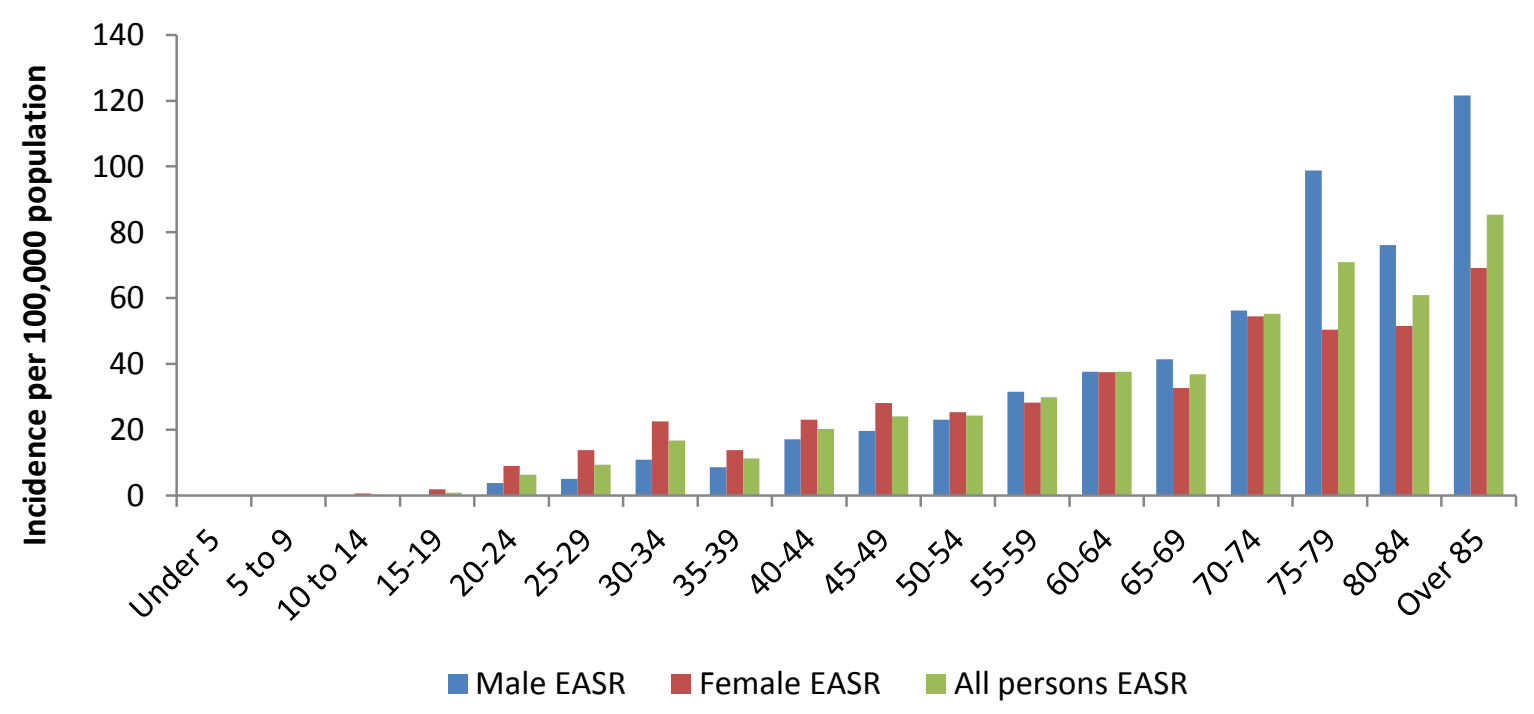

There are differences in the incidence of malignant melanoma in different parts of Scotland. The chart below sets out the rates of malignant melanoma according to patients' health board of residence in 2010. The rates of malignant melanoma varied from 5 per 100,000 population in the Western Isles to 24 per 100,000 in Lanarkshire ${ }^{13}$.

This briefing paper was been drafted on behalf of Skin Cancer UK by MHP Health Mandate Full editorial control rests with Skin Cancer UK, however the final content has been reviewed for factual accuracy by Roche Products Ltd.

Funding for this project has been provided by Roche Products Ltd. 
Figure 3: European age-standardised rates of incidence of malignant melanoma by 100,000 population by health board of residence in $2010^{14}$

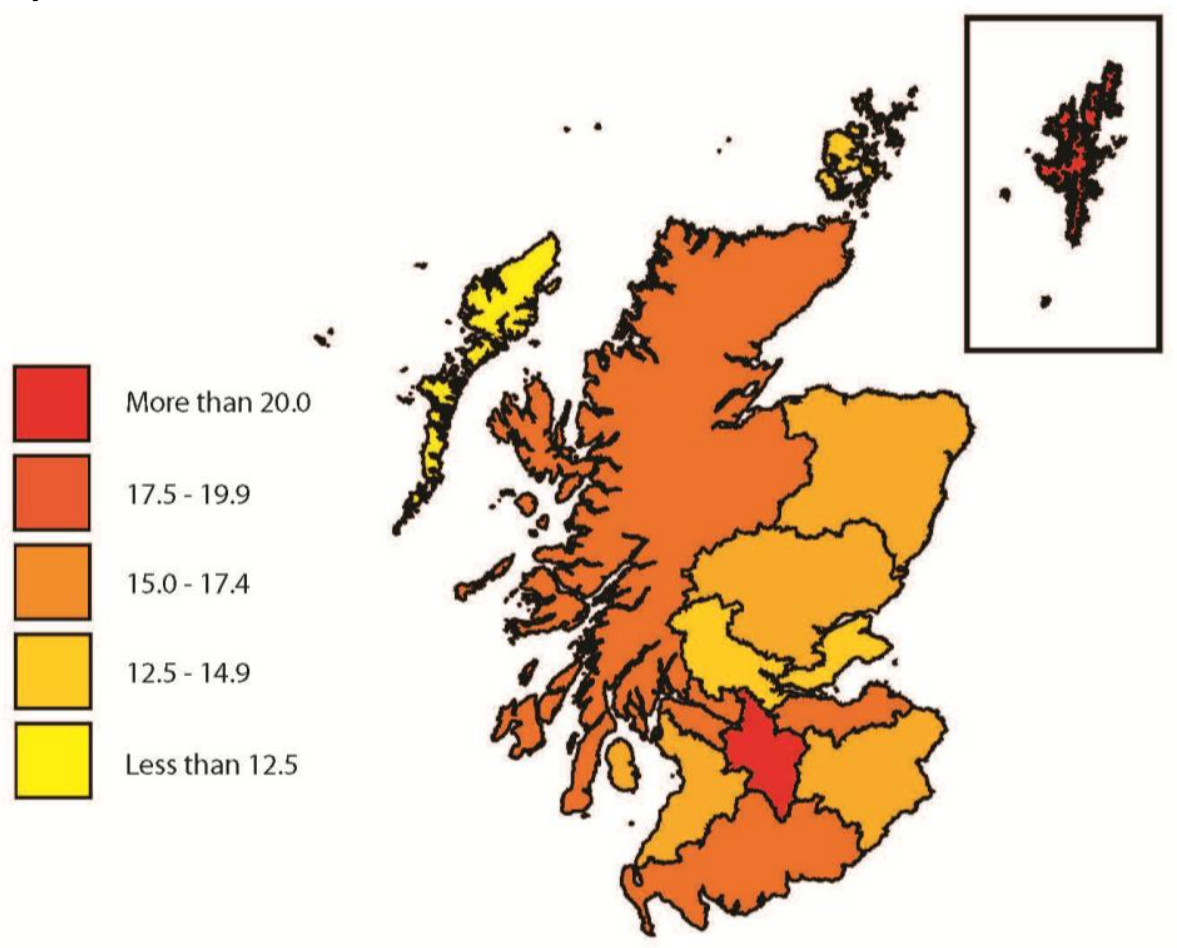

\section{Mortality and survival rates}

There were 176 deaths from malignant melanoma in Scotland in $2011^{15}$. In line with incidence mortality rates have been rising over the last two decades. This increase has been most noticeable in men, with mortality rates for men rising from 1.7 per 100,000 in 1986 to 3.3 in $2011^{16}$. One of the possible explanations for the differences in mortality rates between men and women could be that malignant melanomas in men are more likely to be found on less visible parts of the body. Across the UK, $41 \%$ of melanomas in men are fund on the trunk, particularly the back, whereas for women, almost $40 \%$ of tumours are found on the $\operatorname{leg}^{17}$. This can lead to a delay in patients spotting the signs and symptoms of melanoma and therefore the tumour being more advanced at the time of diagnosis. However, there are likely to be a range of complex factors that play a part in the differences in mortality rates, such as the likelihood of men seeking early medical advice ${ }^{18}$.

This briefing paper was been drafted on behalf of Skin Cancer UK by MHP Health Mandate Full editorial control rests with Skin Cancer UK, however the final content has been reviewed for factual accuracy by Roche Products Ltd.

Funding for this project has been provided by Roche Products Ltd. 
Figure 4: European age-standardised rates of mortality per 100,000 from malignant melanoma in Scotland, 1986-2011 ${ }^{19}$

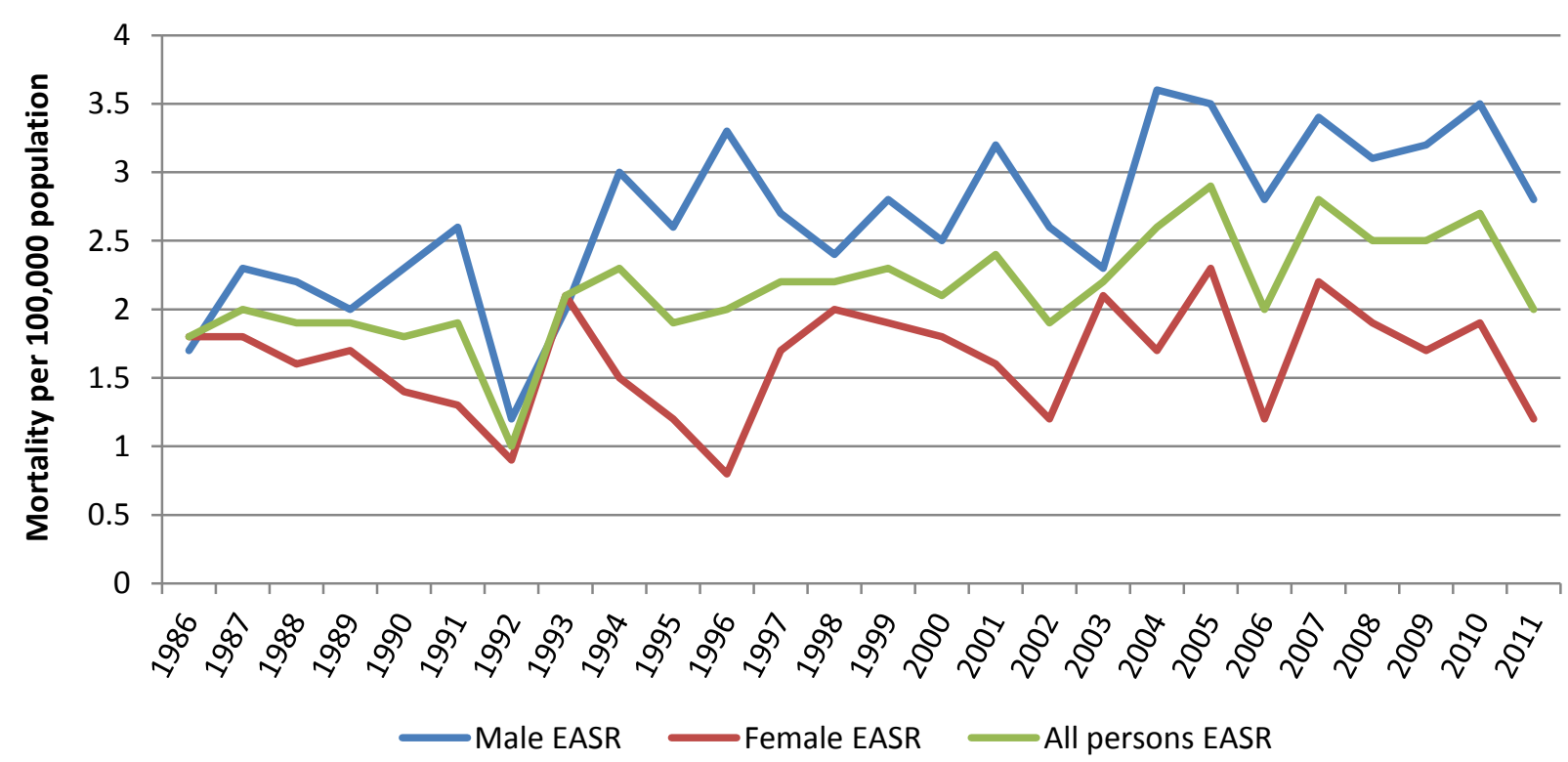

Mortality rates also rise with age, with the majority of deaths from malignant melanoma occurring in those aged over 60 , reflecting the incidence ${ }^{20}$.

As with the rates of incidence, mortality from malignant melanoma varies in different part of Scotland. The mortality rates by health board of residence are set out in Figure 5 .

Figure 5: European age-standardised mortality rates from malignant melanoma in 2011 by health board $^{21}$

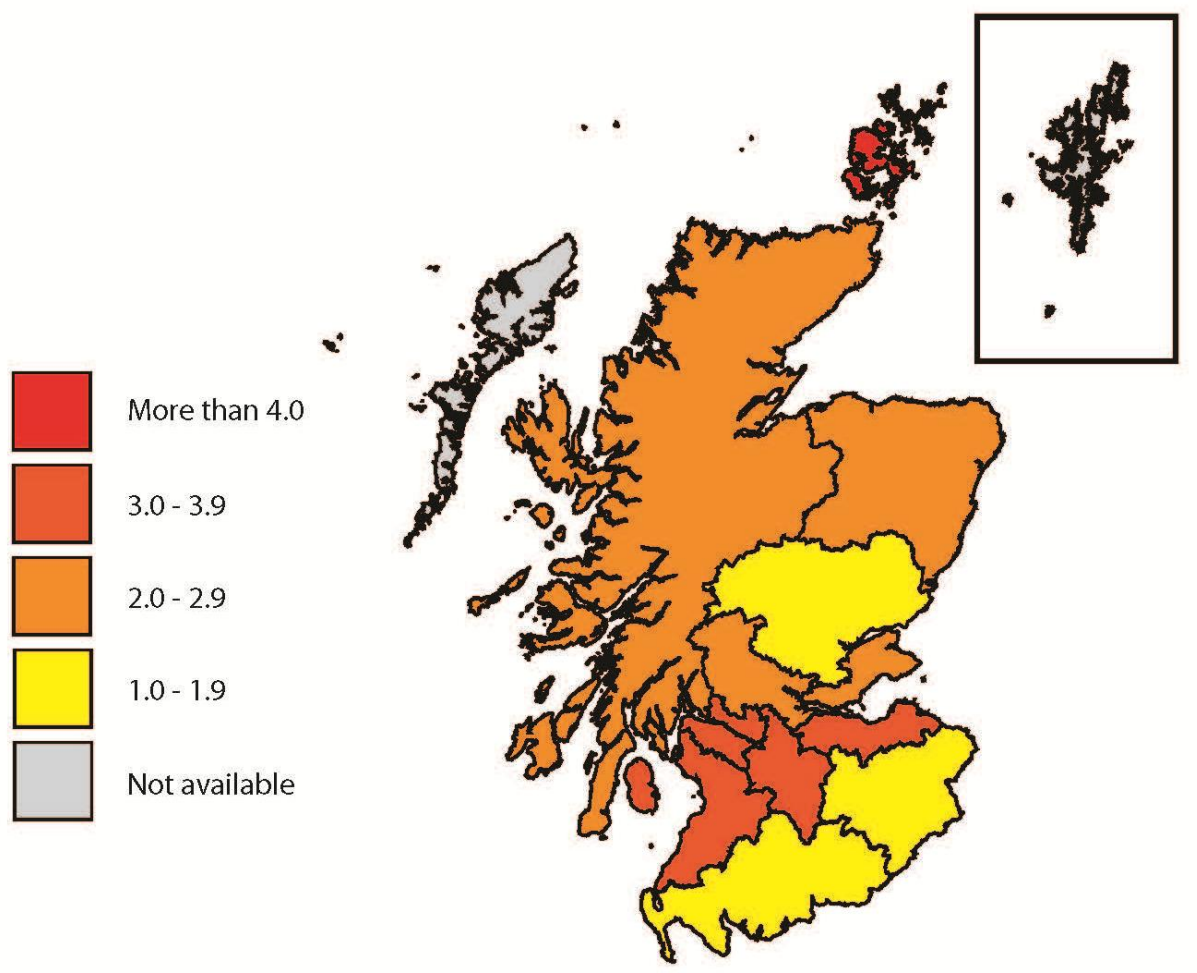

This briefing paper was been drafted on behalf of Skin Cancer UK by MHP Health Mandate Full editorial control rests with Skin Cancer UK, however the final content has been reviewed for factual accuracy by Roche Products Ltd.

Funding for this project has been provided by Roche Products Ltd. 
It is noticeable that the rates of mortality do not match the incidence rates. For example, the Western Isles had the lowest incidence rate but has a mortality rate that is very similar to a number of other boards with a much higher incidence ${ }^{22}$. The differences could be caused by a number of different factors. However, it is vital that health boards ensure that services are in place for the swift diagnosis and treatment of malignant melanoma, including access to new treatments, even where the incidence is relatively low.

Survival rates for people with malignant melanoma are relatively high and have fluctuated only slightly in the last two decades ${ }^{23}$. Survival rates for women remain higher than men.

Figure 6: European standardised relative survival rates for malignant melanoma for people aged 1599 in Scotland, 1983-2007 ${ }^{24}$

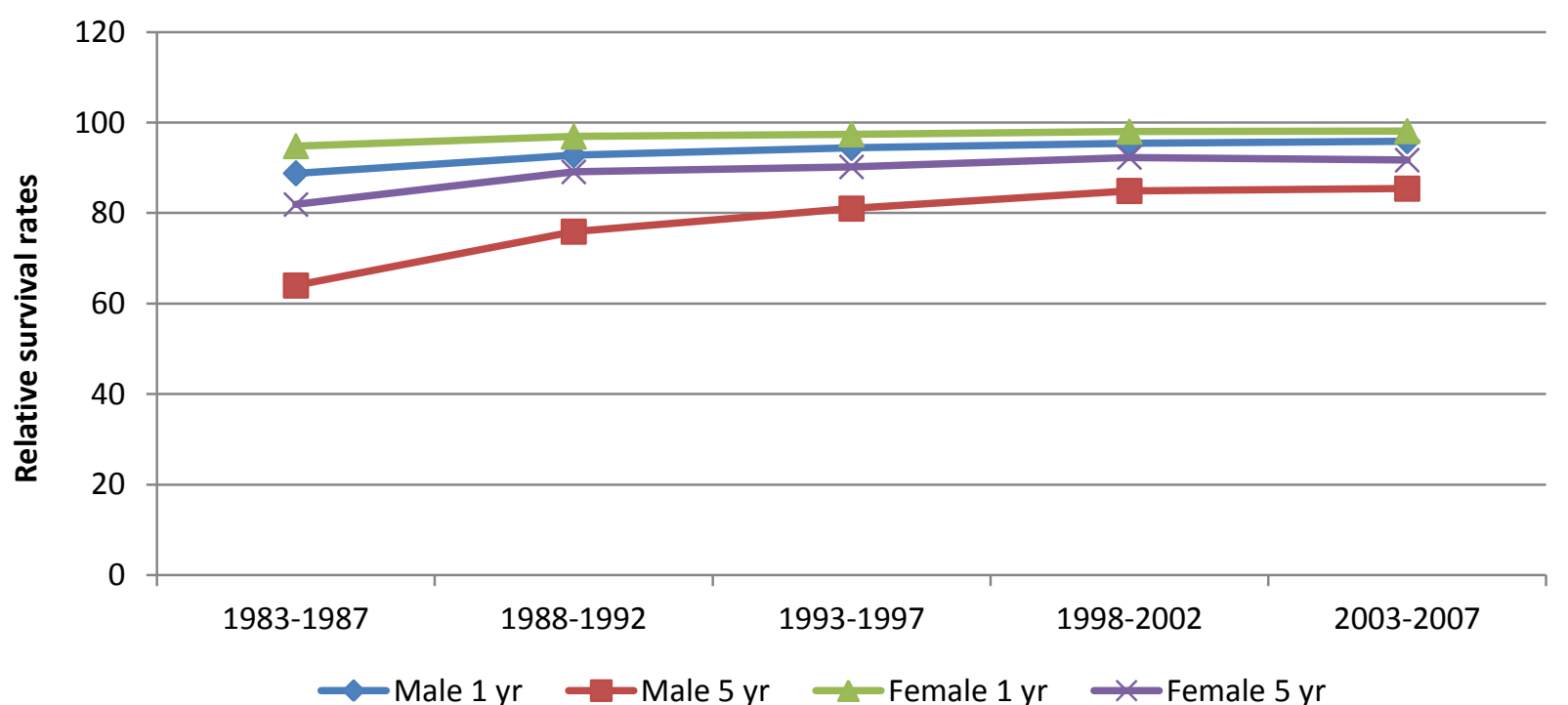

\section{Assessing the quality of care and treatment}

The Scottish Government has introduced strategies to try to improve cancer care, including the publication of Better Cancer Care: An action plan in 2008. This set out around 80 actions in the areas of prevention, early diagnosis, genetic and molecular testing for cancer, referral and diagnosis, treatment, living with cancer, and improving the quality of care ${ }^{25}$. The action plan included specific actions to prevent melanoma, for example by restricting the use of sunbeds by under $18 \mathrm{~s}$ and banning coin-operated or unsupervised sunbeds, which was implemented through the Public Health (Scotland) Act 2008, and a commitment to work with UK-wide organisations to address occupational exposure to the $\operatorname{sun}^{26}$.

Many of the other actions within Better Cancer Care would have been important for improving the care of patients with malignant melanoma. However, it has been difficult to assess progress to date in the absence of annual reports of the improvements made, and particularly for cancers such as melanoma where the numbers of people affected are smaller.

The Detect Cancer Early ${ }^{27}$ initiative builds on the core component of early intervention outlined in Better Cancer Care. Early detection is a critical step towards improving survival - it is the first step

This briefing paper was been drafted on behalf of Skin Cancer UK by MHP Health Mandate

Full editorial control rests with Skin Cancer UK, however the final content has been reviewed for factual accuracy by Roche Products Ltd.

Funding for this project has been provided by Roche Products Ltd. 
towards an improved outcome. It is welcome that the Scottish Government has recognised the importance of early diagnosis and has dedicated funding to the campaign. However, it is disappointing that the initiative does not include malignant melanoma. The guidance for detecting skin cancer is relatively straightforward, particularly with the $A B C D$ of melanoma ${ }^{28}$. The earlier skin cancer is diagnosed the better the chances of successful treatment and we therefore recommend that the Scottish Government includes melanoma in the Detect Cancer Early initiative in 2013.

Alongside early diagnosis, the provision of supportive care, the way services are organised across the pathway, and the quality of different treatments and interventions play a vital role in improving outcomes. It is therefore crucial that patients can access the best possible treatment and care post diagnosis.

\section{Cancer Quality Performance Indicators}

As part of Better Cancer Care the Government made a commitment to develop a series of quality indicators for cancer services to ensure that the NHS focuses on the outcomes that matter most ${ }^{29}$. While this is a positive step forward overall, to date no metrics have been developed for the management of malignant melanoma. Given the reporting requirements for NHS Boards that are associated with quality performance indicators, we believe that indicators should be developed for malignant melanoma as a priority. Both the incidence of malignant melanoma and the mortality rate have been increasing in recent years and it is important that NHS boards are held to account for delivering high quality services that improve the outcomes and experiences of patients.

\section{Patient experience}

NHS Scotland conducts an annual survey of inpatients to gather feedback on their experience. The findings from this survey will help services to identify areas where improvements are needed. However, the generic nature of the survey means that it cannot adequately capture the specific issues that are relevant to patients with cancer. To gain a better understanding of the cancer patient experience, it is important to survey patients on topics such as:

- Engagement with general practice and whether patients had to make multiple visits to get a diagnosis

- Waiting times for treatments

- Written and verbal information provided to patients about their cancer, and their treatment options

- Whether patients were supported to choose their treatments and to manage any side-effects

- Access to support such as clinical nurse specialists

We recommend that a dedicated cancer patient experience survey is established in Scotland to capture the specific experiences of cancer patients, including those with malignant melanoma.

\section{Access to treatment}

For patients with skin cancer, treatment can take a number of forms, including surgery, radiotherapy and drug treatment. Given the rising incidence of skin cancer in Scotland and the focus on earlier detection, it is vital that NHS Boards plan to ensure that services have sufficient capacity and expertise to deliver high quality care.

This briefing paper was been drafted on behalf of Skin Cancer UK by MHP Health Mandate

Full editorial control rests with Skin Cancer UK, however the final content has been reviewed for factual accuracy by Roche Products Ltd.

Funding for this project has been provided by Roche Products Ltd. 
Treatment options for patients with advanced or metastatic malignant melanoma have historically been limited. In the last year there have been major breakthroughs in treatments, with the introduction of two new medicines, however, these have not been recommended for use on the NHS in Scotland ${ }^{30,31}$, whereas in England and Wales they will soon be routinely available following positive guidance from the National Institute for Health and Clinical Excellence (NICE) for both of the new treatments ${ }^{32,33}$. As a result, there is a risk that patients in Scotland will be unable to benefit from these life-extending treatments.

Where drugs have not been approved by the Scottish Medicines Consortium (SMC), the only option is for doctors to make an Individual Patient Treatment Request (IPTR) on behalf of patients to secure funding. As well as there being significant inconsistencies in how IPTRs are implemented by different NHS Boards, in instances when an IPTR is unsuccessful, there are no alternative routes for patients to access these medicines.

This is in stark contrast to the situation in England, where these treatments are currently available to patients through the Cancer Drugs Fund. Recent research has found that patients in Scotland are more than three times less likely to get access to newer cancer medicines funded through the NHS than patients in England ${ }^{34}$. It is important that this inequity is addressed as quickly as possible. Better Cancer Care included commitments on improving the transparency and accessibility to patients of the arrangements for introducing new drugs into NHS Scotland ${ }^{35}$.

We welcome the ongoing work of the Health and Sport Committee ${ }^{36}$ and Scottish Government ${ }^{37}$ to review the approval process for newly licensed medicines and IPTR system. It is imperative that the SMC decision-making process permits sufficient flexibility to ensure that patients in Scotland can have the same access to medicines as patients in England and Wales.

\section{Conclusion}

Despite efforts over recent years to improve the quality of cancer services, the incidence and the mortality rate for malignant melanoma are rising in Scotland. Alongside important prevention efforts, such as the banning of sunbeds, and important work to improve early diagnosis, this should be matched by a renewed focus on improving the quality of services for people living with malignant melanoma. There are several steps that can be taken to achieve this:

- The Scottish Government should work with Health Improvement Scotland on the development of Cancer Quality Performance Indicators for services for malignant melanoma

- Melanoma should be included in the Detect Cancer Early Initiative in 2013

- NHS Scotland should introduce a survey of cancer patients' experiences, to identify areas where improvements in service delivery are required

- The Scottish Government should review the arrangements for making new melanoma treatments available to patients with advanced cancer as a priority

\section{Contact details}

Skin Cancer UK is a coalition of professional groups and charities administered by SKCIN (the Karen Clifford Skin Cancer Charity), committed to tackling this preventable cancer.

This briefing paper was been drafted on behalf of Skin Cancer UK by MHP Health Mandate

Full editorial control rests with Skin Cancer UK, however the final content has been reviewed for factual accuracy by Roche Products Ltd.

Funding for this project has been provided by Roche Products Ltd. 
If you would like more information about our work and how you can support us, please contact Charlotte Fionda on charlotte.fionda@skcin.org or 07834450671.

\section{References}

${ }^{1}$ ISD Scotland, Cancer of the skin - Scotland: trends in incidence 1986-2010, March 2012

${ }^{2}$ ISD Scotland, Cancer of the skin - Scotland: trends in incidence 1986-2010, March 2012

${ }^{3}$ ISD Scotland, Cancer of the skin - Scotland: trends in mortality 1986-2011, September 2012

${ }^{4}$ Scottish Government, Detect Cancer Early, February 2012. Weblink:

http://www.scotland.gov.uk/Topics/Health/Services/Cancer/Detect-Cancer-Early accessed 12 November 2012

${ }_{5}^{5}$ ISD Scotland, Cancer of the skin - Scotland: trends in incidence 1986-2010, March 2012

${ }^{6}$ Scottish Government, Better Cancer Care: An action plan, October 2008

${ }^{7}$ ISD Scotland, Cancer in Scotland, April 2012. Weblink: http://www.isdscotland.org/Health-

Topics/Cancer/Publications/2012-04-24/Cancer in Scotland summary m.pdf accessed 3 October 2012

${ }^{8}$ ISD Scotland, Cancer in Scotland, April 2012. Weblink: http://www.isdscotland.org/Health-

Topics/Cancer/Publications/2012-04-24/Cancer in Scotland summary m.pdf accessed 3 October 2012

${ }^{9}$ ISD Scotland, Cancer of the skin - Scotland: trends in incidence 1986-2010, March 2012

${ }^{10}$ ISD Scotland, Cancer of the skin - Scotland: trends in incidence 1986-2010, March 2012

${ }^{11}$ ISD Scotland, Cancer of the skin - Scotland: trends in incidence 1986-2010, March 2012

${ }^{12}$ ISD Scotland, Cancer of the skin - Scotland: trends in incidence 1986-2010, March 2012

${ }^{13}$ ISD Scotland, Cancer of the skin - Scotland: trends in incidence 1986-2010, March 2012

${ }^{14}$ ISD Scotland, Cancer of the skin - Scotland: trends in incidence 1986-2010, March 2012

${ }^{15}$ ISD Scotland, Cancer of the skin - Scotland: trends in mortality 1986-2011, September 2012

${ }^{16}$ ISD Scotland, Cancer of the skin - Scotland: trends in mortality 1986-2011, September 2012

${ }^{17}$ Cancer Research UK, Skin cancer incidence statistics, July 2012. Weblink: http://www.cancerresearchuk.org/cancerinfo/cancerstats/types/skin/incidence/ accessed 12 November 2012

${ }^{18} \mathrm{NCIN}$, Cancer Research UK, Leeds Metropolitan University and the Men's Health Forum, Excess burden of cancer in men in the UK, August 2010

${ }_{19}^{1}$ ISD Scotland, Cancer of the skin - Scotland: trends in mortality 1986-2011, September 2012

${ }^{20}$ ISD Scotland, Cancer of the skin - Scotland: trends in mortality 1986-2011, September 2012

${ }^{21}$ ISD Scotland, Cancer of the skin - Scotland: trends in mortality 1986-2011, September 2012

${ }^{22}$ ISD Scotland, Cancer of the skin - Scotland: trends in mortality 1986-2011, September 2012

${ }^{23}$ ISD Scotland, Cancer of the skin - Scotland: trends in survival by age group and period of diagnosis, June 2010

${ }^{24}$ ISD Scotland, Cancer of the skin - Scotland: trends in survival by age group and period of diagnosis, June 2010

${ }^{25}$ Scottish Government, Better Cancer Care: An action plan, October 2008

${ }^{26}$ Scottish Government, Better Cancer Care: An action plan, October 2008

${ }^{27}$ Scottish Government, Detect Cancer Early, February 2012. Weblink:

http://www.scotland.gov.uk/Topics/Health/Services/Cancer/Detect-Cancer-Early accessed 12 November 2012

${ }^{28}$ Skcin, How to detect skin cancer, 2012. Weblink: http://www.skcin.org/Skin-Cancer/How-to-Detect-Skin-Cancer accessed 3 October 2012

${ }^{29}$ Scottish Government, Better Cancer Care: An action plan, October 2008

${ }^{30}$ Scottish Medicines Consortium, SMC No. (779/12) ipilimumab (Yervoy $\left.{ }^{\circledR}\right) 5 \mathrm{mg} / \mathrm{mL}$ concentrate for solution for infusion, April 2012

${ }^{31}$ Scottish Medicines Consortium, SMC No. (792/12) vemurafenib 240mg film-coated tablet (Zelboraf ${ }^{\circledast}$ ), August 2012

${ }^{32}$ National Institute for Health and Clinical Excellence, Final appraisal determination: Vemurafenib for treating locally advanced or metastatic BRAF V600 mutation-positive malignant melanoma, November 2012

${ }^{33}$ National Institute for Health and Clinical Excellence, Final appraisal determination: Ipilimumab for previously treated (unreselectable or metastatic) melanoma, November 2012

${ }^{34}$ Rarer Cancers Foundation, Nations divided? An assessment of variations in access to cancer treatments for patients in England, Scotland and Wales, August 2011

${ }^{35}$ Scottish Government, Better Cancer Care: An action plan, October 2008

${ }^{36}$ Health and Sport Committee, Access to newly licensed medicines, 2012. Weblink:

http://www.scottish.parliament.uk/parliamentarybusiness/CurrentCommittees/52064.aspx accessed on 22 November 2012

${ }^{37}$ Scottish Government, New medicines review, 14 November 2012. Weblink:

http://www.scotland.gov.uk/News/Releases/2012/11/review14112012 accessed on 22 November 2012

This briefing paper was been drafted on behalf of Skin Cancer UK by MHP Health Mandate

Full editorial control rests with Skin Cancer UK, however the final content has been reviewed for factual accuracy by Roche Products Ltd.

Funding for this project has been provided by Roche Products Ltd. 